\title{
Role of Silver Incorporation on the Specific Heat in Glassy $\mathrm{Se}_{80} \mathrm{Te}_{20}$ Alloy
}

\author{
Shipra Saraswat*, Surendra Dutt Sharma \\ Department of Chemistry, IFTM University, Moradabad, India \\ Email: ${ }^{*}$ dr shipra_saraswat@yahoo.com
}

Received 25 August 2014; revised 16 September 2014; accepted 14 October 2014

Copyright (C) 2014 by authors and Scientific Research Publishing Inc.

This work is licensed under the Creative Commons Attribution International License (CC BY). http://creativecommons.org/licenses/by/4.0/

(c) (i) Open Access

\begin{abstract}
Specific heat measurements have been made in glassy $\operatorname{Se}_{80-\mathrm{x}} \mathrm{Te}_{20} \mathrm{Ag}_{\mathrm{x}}(0 \leq \mathrm{x} \leq 15)$ alloys using differential scanning calorimetry (DSC) technique. An extremely large increase in the specific heat values has been observed at the glass transition temperature. It has also been found that the values of $C_{p}$ below glass transition temperature and the difference of $C_{p}$ values before and after glass transition $\left(\Delta \mathrm{C}_{\mathrm{p}}\right)$ are highly composition dependent. This indicates that the incorporation of $\mathrm{Ag}$ in binary $\mathrm{Se}_{80} \mathrm{Te}_{20}$ alloy in the present study influences the structure of the binary alloy. Specific heat of the additive element Ag is found to be important for the observed changes in the specific heat of the ternary alloys as compared to binary alloy.
\end{abstract}

\section{Keywords}

\section{Chalcogenide Glasses, Differential Scanning Calorimetry, Glass Transition, Specific Heat}

\section{Introduction}

Chalcogenide glasses belong to family of non-oxide glassy alloys, which contain a large amount of chalcogen elements Se, S and Te from VI group of the Periodic Table. These glasses behave as semiconductor. A variety of stable glasses have been prepared in bulk, fiber, thin film and multilayer forms using melt quenching, vacuum deposition and various other less common techniques. These glasses are being used in computer memories, erasable high density optical memories, photoconductive applications such as photoreceptors in copying machines and X-ray imaging plates, I.R. optical lenses and windows and high sensitivity ionic sensors [1]-[4] using silver doped chalcogenide glasses. Due to these technical advantages of chalcogenide glasses, these materials are being studied all over the world by scientists as well as engineers.

One of the most significant problems in the area of glasses is the understanding of glass transition temperature

${ }^{*}$ Corresponding author. 
and structural relaxation [5]-[9]. The glass transition is exhibited as an endothermic peak or a shift in the base line in the scan of Differential Scanning Calorimetry (DSC) due to change in specific heat.

Specific heat is very sensitive to the way in which atoms or molecules are dynamically bound in a solid [10]. Thus the measurement of such parameter like heat capacity will lead to a valuable test for characterizing material as glassy substance. An abrupt change in specific heat at the glass transition is characteristic of all chalcogenide glasses. The parameter detects sensitively the change in the microstructure of the glass which can be seen by the jump of the specific heat close to the Dulong and the Petit value $C_{p}=3 R$. Some attempts have been made to measure the specific heat of chalcogenide glasses in old [11]-[17] and recent past [18] [19]. However, the explanations for the change in specific heat before and after glass transition are of diversified in nature. More experimental work is required in this direction.

Chalcogenide glasses containing Ag have attracted much interest in glass science and technology for fundamental research of their structure, properties and preparation [20]. They have many current and potential applications in optics, optoelectronics, chemistry and biology such as optical elements, gratings, photo-doping, optical memories, microlenses, waveguides, holography, bio- and chemical-sensors, solid electrolytes, batteries etc. [20].

One other aspect of silver's influence in Ag-containing chalcogenide glasses is the effect on the electrical conductivity of the glasses, which can be changed by several orders of magnitudes when $\mathrm{Ag}$ is introduced. Therefore, investigations on the influence of Ag on the electrical properties of chalcogenide glasses are of relevance both from the basic science and application point of view. The low free energy of crystallization of Ag (48 $\mathrm{kcal} / \mathrm{mol}$ ) was a further reason to consider the introduction of Ag in chalcogenide glasses used for phase change optical recording [21]-[24]. This is one of the main requirements for good optical recording-high phase transformation rate.

Chalcogenide glasses containing Ag, generally, exhibit single glass transition and single crystallization temperature, which is an important condition for rewritable disks. Thin films of chalcogenide glasses containing Ag have been found application in erasable PC optical recording [20]. Different Ag doped chalcogenide alloys have been developed as recording layer and their good practical performance has been reported [20]. The electrical, optical and structural properties of Ag doped chalcogenide glasses have been studied by various workers [25]-[27] but no serious attempts have been made to report specific heat studies in these materials [28]. This motivated us to start work in this direction. The present paper reports the effect of Ag additives on the specific heat in binary $\mathrm{Se}_{80} \mathrm{Te}_{20}$ alloy.

\section{Experimental}

Glassy alloys of $\mathrm{Se}_{80-\mathrm{x}} \mathrm{Te}_{20} \mathrm{Ag}_{\mathrm{x}}(0 \leq \mathrm{x} \leq 15)$ were prepared by quenching technique. High purity materials $(5 \mathrm{~N}$ pure) were weighed according to their atomic percentages and were sealed in quartz ampoules under the vacuum of $10^{-5}$ Torr. Each ampoule was kept inside the furnace at $1000^{\circ} \mathrm{C}$ (where the temperature was raised at a rate of $3^{\circ} \mathrm{C}-4^{\circ} \mathrm{C} / \mathrm{min}$ ). The ampoules were rocked frequently for $10 \mathrm{hrs}$ at the maximum temperature to make the melt homogeneous. Quenching was done in ice water and the glassy nature of alloys was checked by X-ray diffraction technique. The XRD pattern of ternary $\mathrm{Se}_{70} \mathrm{Te}_{20} \mathrm{Ag}_{10}$ alloy is shown in Figure 1. The absence of any sharp peak confirms the glassy nature of alloy. Similar XRD patters were obtained for other glasses.

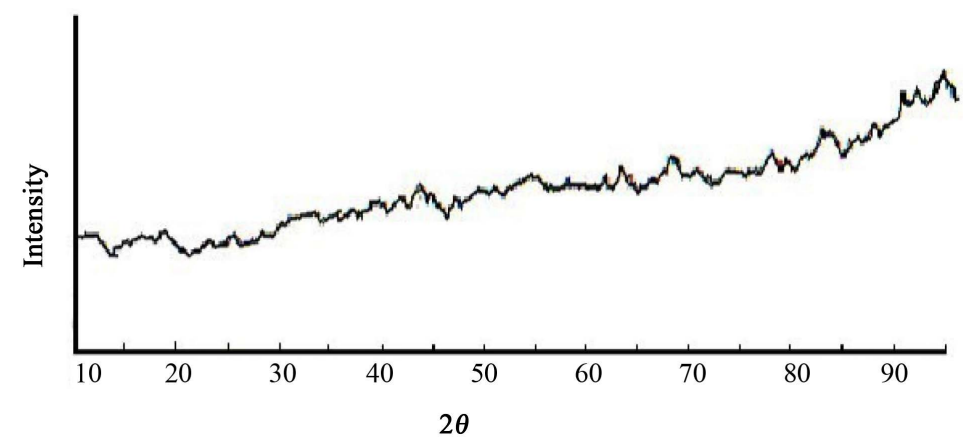

Figure 1. XRD pattern of ternary $\mathrm{Se}_{70} \mathrm{Te}_{20} \mathrm{Ag}_{10}$ alloy. Absence of sharp peaks is indication of glassy nature of the sample. 
The glasses, thus prepared, were ground to make fine powder for DSC studies. Constant heating rate of 10 $\mathrm{K} / \mathrm{min}$ was used for DSC scans. Then 5 - $10 \mathrm{mg}$ of the sample was kept inside in the pans and then thermoscans were recorded under almost identical conditions.

Measurements were made under almost identical conditions so that a comparison of specific heat $\mathrm{C}_{\mathrm{p}}$ could be made in order to understand the effect of changing the composition of $\mathrm{Ag}$ in binary $\mathrm{Se}_{80} \mathrm{Te}_{20}$ alloy. Using these plots, the specific heat of each alloy is measured at different temperature in the glass transition region.

\section{Results and Discussions}

Figure 2 shows the typical DSC thermogram for ternary alloy $\mathrm{Se}_{70} \mathrm{Te}_{20} \mathrm{Ag}_{10}$ at the heating rate of $10 \mathrm{~K} / \mathrm{min}$. Similar thermograms were obtained for other glassy alloys. When a material is subjected to a linear temperature programme, the heat flow rate into the sample is proportional to its instantaneous specific heat. Since the scanning rate of the DSC analyzer is linear and the instrument measures heat flow directly, the specific heat of a sample material is easily calculated.

The variation of $C_{p}$ as a function of temperature at the heating rate of $10 \mathrm{~K} / \mathrm{min}$ for each glassy alloy is shown in Figure 3. It is clear from this figure that below glass transition temperature, $C_{p}$ is weakly temperature dependent. However, near glass transition temperature, $C_{p}$ increases drastically with the increase of temperature and shows maxima at glass transition temperature. After glass transition temperature, $C_{p}$ attains a stable value which is slightly higher as compared to $C_{p}$ below glass transition temperature. The sudden jump in $C_{p}$ value for each alloy at glass transition can be attributed [29] to anharmonic contribution to the specific heat. The overshoot in the value of $C_{p}$ at the upper end of the " $C_{p}$ jump" at glass transition is due to the relaxation effects. The time scale [30] for structural relaxation is highly dependent both on temperature and on the instantaneous structure itself. The observed peak in $C_{p}$ at glass transition temperature $T_{g}$ may be due to the fact that the structural relaxation times at this temperature becomes of the same order as the time scale of the experiment.

The difference of specific heat values $\left(\Delta \mathrm{C}_{\mathrm{p}}\right)$ after glass transition (i.e., equilibrium liquid specific heat $\mathrm{C}_{\mathrm{pe}}$ ) and before glass transition (i.e., glass specific heat $\mathrm{C}_{\mathrm{pg}}$ ) has been calculated for each glassy alloy and the values of $\mathrm{C}_{\mathrm{pe}}, \mathrm{C}_{\mathrm{pg}}$ and $\Delta \mathrm{C}_{\mathrm{p}}$ are given in Table 1. From this table, it is observed that the value of glass specific heat $\mathrm{C}_{\mathrm{pg}}$ and equilibrium liquid specific heat $\mathrm{C}_{\mathrm{pe}}$ are higher for ternary alloys as compared to binary alloy $\mathrm{Se}_{80} \mathrm{Te}_{20}$ (see Table 1).

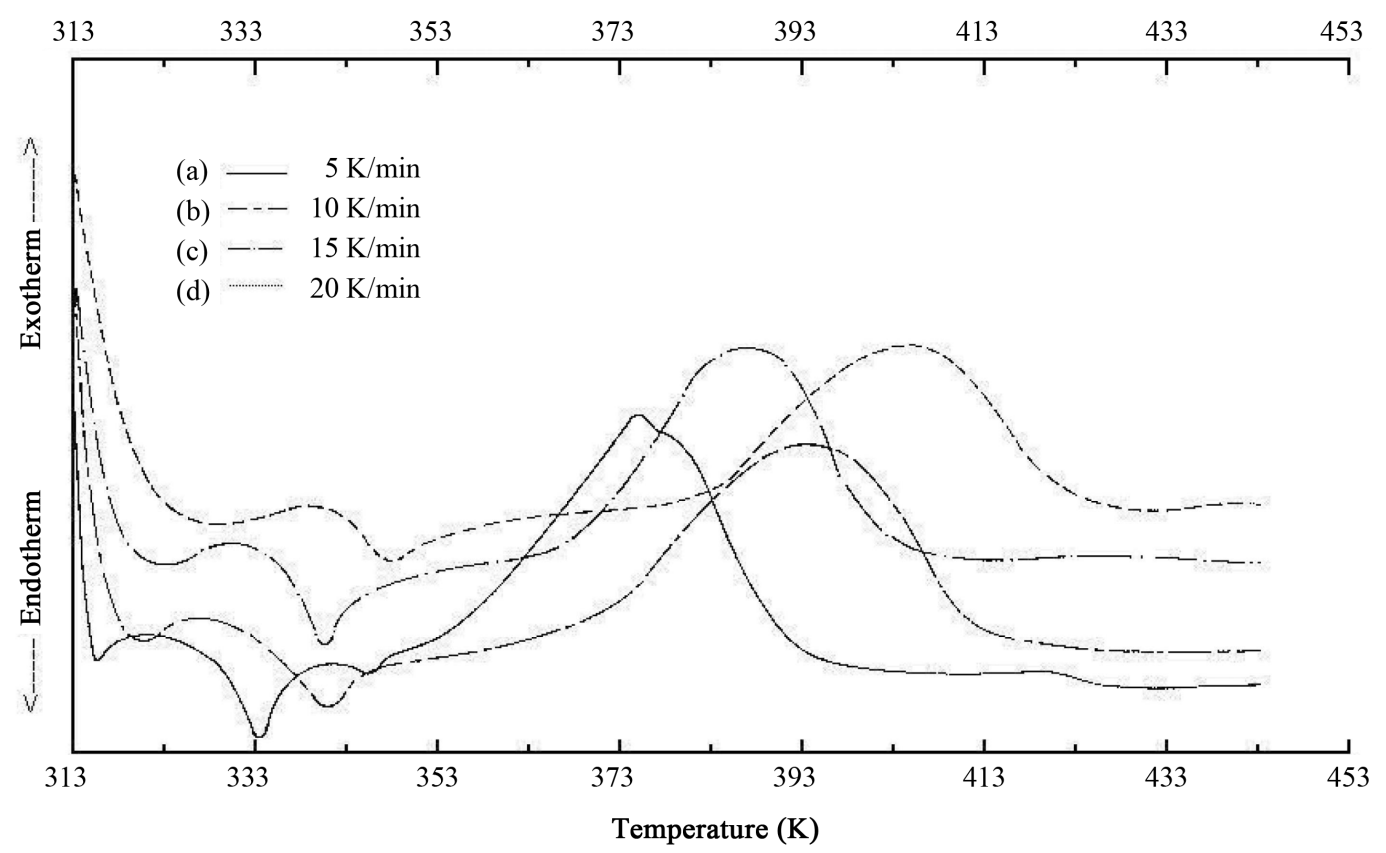

Figure 2. DSC thermograms of ternary $\mathrm{Se}_{70} \mathrm{Te}_{20} \mathrm{Ag}_{10}$ alloy at different heating rates. Endothermic peaks show the occurrence of glass transition phenomenon in the sample. Exothermic peaks indicate the thermally activated non-isothermal crystallization of the sample. 

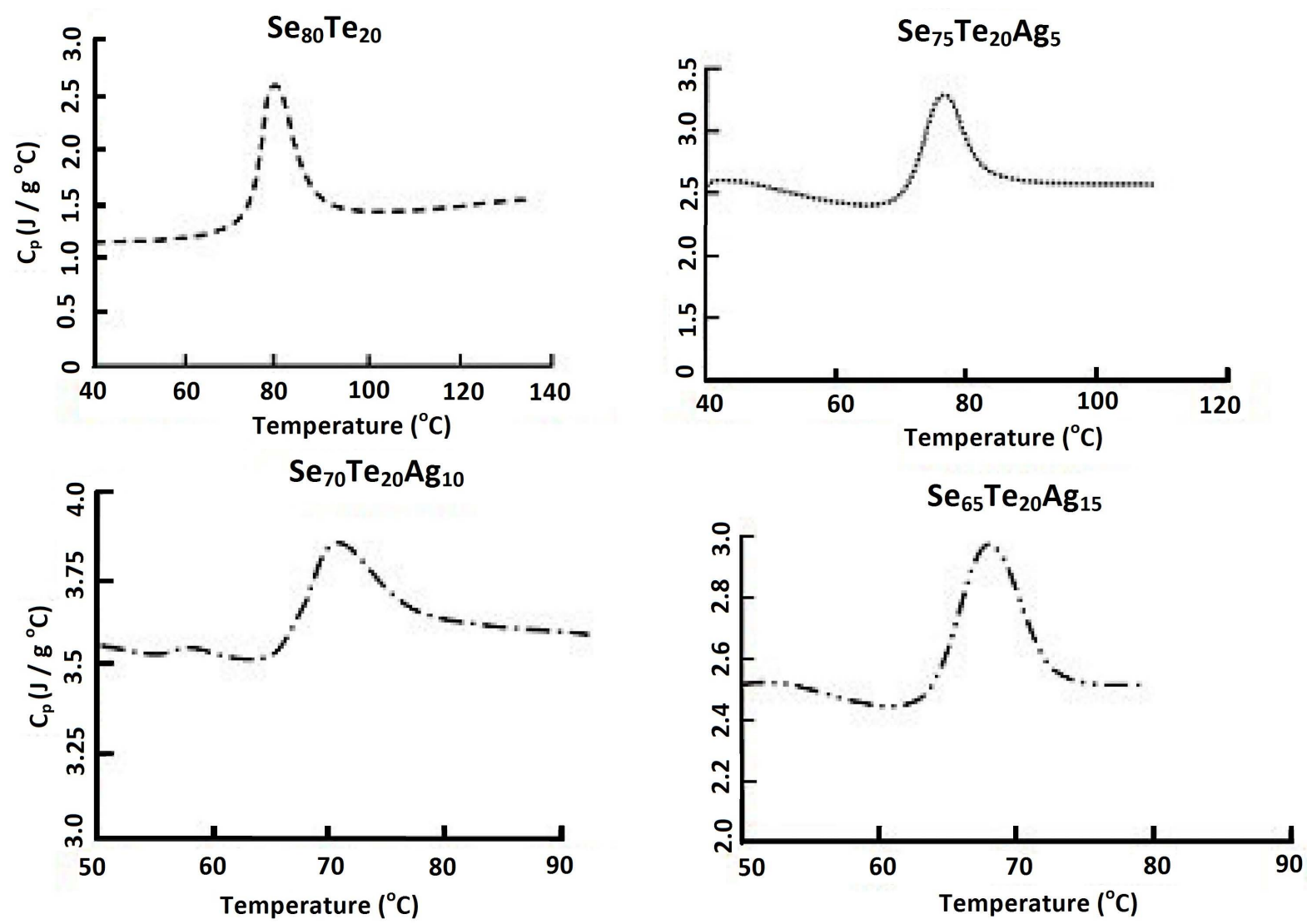

Figure 3. Temperature dependence of specific heat for glassy $\mathrm{Se}_{80-\mathrm{x}} \mathrm{Te}_{20} \mathrm{Ag}_{\mathrm{x}}(0 \leq \mathrm{x} \leq 15)$ alloys. The on-set value of peak indicates the glass specific heat $\mathrm{C}_{\mathrm{pg}}$, whereas the off-set value of peak provides the value of equilibrium specific heat $\mathrm{C}_{\mathrm{pe}}$.

Table 1. Values of various specific heat parameters for glassy $\mathrm{Se}_{80-\mathrm{x}} \mathrm{Te}_{20} \mathrm{Ag}_{\mathrm{x}}(0 \leq \mathrm{x} \leq 15)$ alloys.

\begin{tabular}{cccc}
\hline Sample & $\mathrm{C}_{\mathrm{pe}}$ & $\mathrm{C}_{\mathrm{pg}}$ & $\Delta \mathrm{C}_{\mathrm{p}}$ \\
\hline $\mathrm{Se}_{80} \mathrm{Te}_{20}$ & 1.45 & 1.23 & 0.22 \\
$\mathrm{Se}_{75} \mathrm{Te}_{20} \mathrm{Ag}_{5}$ & 2.72 & 2.43 & 0.29 \\
$\mathrm{Se}_{70} \mathrm{Te}_{20} \mathrm{Ag}_{10}$ & 3.63 & 3.52 & 0.11 \\
$\mathrm{Se}_{65} \mathrm{Te}_{20} \mathrm{Sb}_{15}$ & 2.55 & 2.46 & 0.09 \\
\hline
\end{tabular}

This increase in $\mathrm{C}_{\mathrm{pe}}$ and $\mathrm{C}_{\mathrm{pg}}$ of ternary Se-Te-Ag alloys can be explained in terms of atomic weights of Se and Ag. The additive element (Ag) is added in Se-Te system at the cost of Se in the present glassy system. The atomic weight of $\mathrm{Ag}(107.87 \mathrm{gm} / \mathrm{mol})$ is more than that of Se $(78.96 \mathrm{gm} / \mathrm{mol})$. It is well-known that during the glass transition phenomenon in chalcogenide glasses, some thermally-induced structural relaxation takes place in the glassy network. The atomic weight of Se $(78.96 \mathrm{gm} / \mathrm{mol})$ is less than that of Ag $(107.87 \mathrm{gm} / \mathrm{mol})$. Thus more specific heat is required for structural rearrangements with the increase in the mean atomic weights in ternary alloys. This is probably the reason for increase in $C_{p}$ values after incorporation of Ag. Similar behavior was observed by our group in another glassy system [19].

\section{Conclusion}

Calorimetric measurements have been performed in glassy $\operatorname{Se}_{80-\mathrm{x}} \mathrm{Te}_{20} \mathrm{Ag}_{\mathrm{x}}(0 \leq \mathrm{x} \leq 15)$ alloys to study the effect of $\mathrm{Ag}$ additive on the specific heat in glassy $\mathrm{Se}_{80} \mathrm{Te}_{20}$ alloy. The values of $\mathrm{C}_{\mathrm{p}}$ have been found to be increased in ternary alloys due to incorporation of third element (Ag) in Se-Te system. This indicates that the Ag additive drastically changes the structure of the binary $\mathrm{Se}_{80} \mathrm{Te}_{20}$ glassy alloy. The composition dependence of the specific 
heat, $\mathrm{C}_{\mathrm{p}}$, of equilibrium liquid and glass specific heat, $\mathrm{C}_{\mathrm{pg}}$, in glassy $\mathrm{Se}_{80-\mathrm{x}} \mathrm{Te}_{20} \mathrm{Ag}_{\mathrm{x}}(0 \leq \mathrm{x} \leq 15)$ system is explained in terms of mean atomic masses of ternary alloys.

\section{Acknowledgements}

S. S. thanks to Prof. Ashok Kumar, Harcourt Butler Technological Institute, Kanpur India for providing experimental facilities and useful discussion.

\section{References}

[1] Mehta, N. (2006) Applications of Chalcogenide Glasses in Electronics and Optoelectronics: A Review. Journal of Scientific \& Industrial Research, 65, 777-786.

[2] Andriesh, A.M., Iovu, M.S. and Shutov, S.D. (2002) Competitive Photostructural Effects in Ge-Se Glass. Journal of Optoelectronics and Advanced Materials, 4, 631-647.

[3] Yamada, N. (1996) Erasable Phase-Change Optical Materials. MRS Bulletin, 21, 48-50.

[4] Ohta, T. (2001) Phase-Change Optical Memory Promotes the DVD Optical Disk. Journal of Optoelectronics and Advanced Materials, 3, 609-626.

[5] Lankhorst, M.H.R. (2002) Modelling Glass Transition Temperature of Chalcogenide Glasses Applied to Phase-Change Optical Recording Materials. Journal of Non-Crystalline Solids, 297, 210-219. http://dx.doi.org/10.1016/S0022-3093(01)01034-1

[6] Khan, S.A., Zulfequar, M. and Husain, M. (2002) On the Crystallization Kinetics of Amorphous $\mathrm{Se}_{80} \mathrm{Te}_{20-\mathrm{P}} \mathrm{Pb}_{\mathrm{x}}$. Solid State Communications, 123, 463-468. http://dx.doi.org/10.1016/S0038-1098(02)00147-3

[7] El-Oyoun, M.A., Shurit, G.M., Gaber, A. and Afify, N. (2003) Differential Scanning Calorimetric Study of $\mathrm{Ga}_{5} \mathrm{Se}_{95}$ Glass. Journal of Physics and Chemistry of Solids, 64, 821-826. http://dx.doi.org/10.1016/S0022-3697(02)00412-2

[8] Kumar, H., Mehta, N., Singh, K. and Saxena, N.S. (2010) Effect of Lithium Ion Irradiation on the Glass Transition Kinetics of $\mathrm{Se}_{98} \mathrm{In}_{2}$ Chalcogenide Glass. Phase Transitions, 83, 1-9. http://dx.doi.org/10.1080/01411590903509504

[9] Pustkova, P., Shanelova, J., Cicmanec, P. and Malek, J. (2003) Structural Relaxation of Amorphous $\mathrm{Ge}_{38} \mathrm{~S}_{62}$ Studied by Length Dilatometry and Calorimetry. Journal of Thermal Analysis and Calorimetry, 72, 355. http://dx.doi.org/10.1023/A:1023965029780

[10] Ma, H.L., Zhang, X.H., Lucas, J. and Moyanihan, C.T. (1992) Relaxation near Room Temperature in Tellurium Chalcohalide Glasses. Journal of Non-Crystalline Solids, 140, 209. http://dx.doi.org/10.1016/S0022-3093(05)80768-9

[11] Agarwal, P., Rai, J.S.P. and Kumar, A. (1993) Heat Capacities of $\mathrm{Se}_{100-\mathrm{x}} \mathrm{Te}_{\mathrm{x}}$ Glasses. Indian Journal of Pure and Applied Physics, 31, 502-503.

[12] Kabinal, M.K., Sangunni, K.S., Subramanyam, S.V. and Gopal, E.S.R. (1995) Specific Heat Measurements on Ge-Se-In Glasses. Physics and Chemistry of Glasses, 36, 50-52.

[13] Pradeep, P., Saxena, N.S., Saksena, M.P. and Kumar, A. (1996) Heat Capacities and Relaxation Effects of Se-Te-Cd Glasses. Physica Status Solidi (a), 155, 333-339. http://dx.doi.org/10.1002/pssa.2211550206

[14] Wagner, T., Frumar, M. and Kasap, S.O. (1999) Glass Transformation, Heat Capacity and Structure of $\mathrm{Ag}_{x}\left(\mathrm{As}_{0.4} \mathrm{Se}_{0.6}\right)_{100-x}$ Glasses Studied by Temperature-Modulated Differential Scanning Calorimetry. Journal of Non-Crystalline Solids, 256-257, 160-164.

[15] Pradeep, P., Saxena, N.S. and Kumar, A. (1997) Crystallization and Specific Heat Studies of $\mathrm{Se}_{100-x} \mathrm{Sb}_{x}(x=0,2$ and 4) Glass. Journal of Physics and Chemistry of Solids, 58, 385-389. http://dx.doi.org/10.1016/S0022-3697(96)00148-5

[16] Alake, T., Abe, R., Honda, K., Kawaji, H., Johnsen, H.B. and Stolen, S. (2000) Heat Capacities of Glassy and Crystalline GeSe ${ }_{2}$. Journal of Physics and Chemistry of Solids, 61, 1373-1377. http://dx.doi.org/10.1016/S0022-3697(00)00022-6

[17] Tiwari, R.S., Mehta, N., Shukla, R.K. and Kumar, A. (2005) Thermal Characterisation of Some Se-Ge-In Chalcogenide Glasses by Differential Scanning Calorimetry. Physics and Chemistry of Glasses, 46, 595-599.

[18] Saraswat, S. and Kushwaha, S.S.S. (2009) Structural Interpretation of Specific Heat Measurements on Glassy $\mathrm{Se}_{100-x} \mathrm{Sb}_{x}$ Alloys. Philosophical Magazine, 89, 583-593. http://dx.doi.org/10.1080/14786430902720945

[19] Saraswat, S. and Kushwaha, S.S.S. (2009) Specific Heat Studies in a-Se and a-Se ${ }_{90} \mathrm{M}_{10}(\mathrm{M}=\mathrm{In}, \mathrm{Sb}, \mathrm{Te})$ Alloys. Journal of Thermal Analysis and Calorimetry, 96, 923-927. http://dx.doi.org/10.1007/s10973-009-0065-9

[20] Frumar, M. and Wagner, T. (2003) Ag Doped Chalcogenide Glasses and Their Applications. Current Opinion in Solid State and Materials Science, 7, 117-126.

[21] Tanaka, K., Itoh, M., Yoshida, N. and Ohta, M. (1995) Photoelectric Properties of Ag-As-S Glasses. Journal of Ap- 
plied Physics, 78, 3895-3901. http://dx.doi.org/10.1063/1.359906

[22] Kawaguchi, T., Maruno, S. and Elliott, S.R. (1996) Optical, Electrical, and Structural Properties of Amorphous Ag-Ge-S and Ag-Ge-Se Films and Comparison of Photoinduced and Thermally Induced Phenomena of Both Systems. Journal of Applied Physics, 79, 9096-9104. http://dx.doi.org/10.1063/1.362644

[23] Ohta, M. (1997) Effect of Small Amounts of Silver on the Electrical Properties of $\mathrm{As}_{2} \mathrm{~S}_{3}$ Glasses. Physica Status Solidi (a), 159, 461-468. http://dx.doi.org/10.1002/1521-396X(199702)159:2<461::AID-PSSA461>3.0.CO;2-W

[24] Wagner, T., Frumar, M. and Suskova, V. (1991) Photoenhanced Dissolution and Lateral Diffusion of Ag in Amorphous As-S Layers. Journal of Non-Crystalline Solids, 128, 197-207.

[25] Srivastava, A., Kushwaha, V.S. and Mehta, N. (2014) Effect of Ag Incorporation on the Correlation between Pre-Exponential Factor and Activation Energy of Thermally Activated High Field Conduction in $\mathrm{Ge}_{20} \mathrm{Se}_{80}$ Alloy. Journal of Advanced Physics, 2, 265-269. http://dx.doi.org/10.1166/jap.2013.1079

[26] Ramesh, K., Asokan, S., Sangunni, K.S. and Gopal, E.S.R. (2000) Glass Formation in Germanium Telluride Glasses Containing Metallic Additives. Journal of Physics and Chemistry of Solids, 61, 95-101. http://dx.doi.org/10.1016/S0022-3697(99)00239-5

[27] Frumar, M., Cernosek, Z., Jedelsky, J., Frumarova, B. and Wagner, T. (2001) Photoinduced Changes of Structure and Properties of Amorphous Binary and Ternary Chalcogenides. Journal of Optoelectronics and Advanced Materials, 3, 177-126.

[28] Tiwari, R.S., Mehta, N., Shukla, R.K. and Kumar, A. (2006) Composition Dependence of Specific Heat in $\mathrm{Se}_{70-\mathrm{x}} \mathrm{Te}_{20} \mathrm{Ag}_{\mathrm{x}}$ Chalcogenide Glasses. Journal of Ovonic Research, 2, 53-59.

[29] Mahadevan, S., Giridhar, A. and Singh, A.K. (1986) Calorimetric Measurements on As-Sb-Se Glasses. Journal of Non-Crystalline Solids, 88, 11-34.

[30] Ma, H.L., Zhang, X.H. and Lucas, J. (1992) Relaxation near Room Temperature in Tellurium Chalcohalide Glasses. Journal of Non-Crystalline Solids, 140, 209-214. 
Scientific Research Publishing (SCIRP) is one of the largest Open Access journal publishers. It is currently publishing more than 200 open access, online, peer-reviewed journals covering a wide range of academic disciplines. SCIRP serves the worldwide academic communities and contributes to the progress and application of science with its publication.

Other selected journals from SCIRP are listed as below. Submit your manuscript to us via either submit@scirp.org or Online Submission Portal.
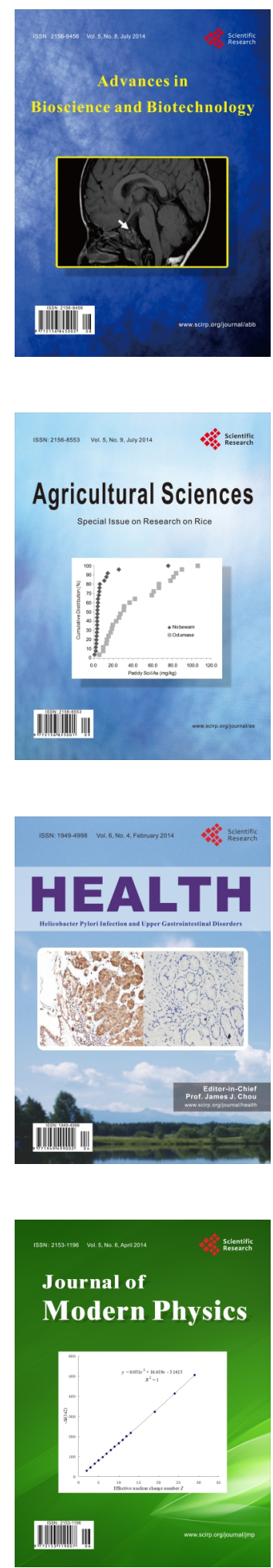
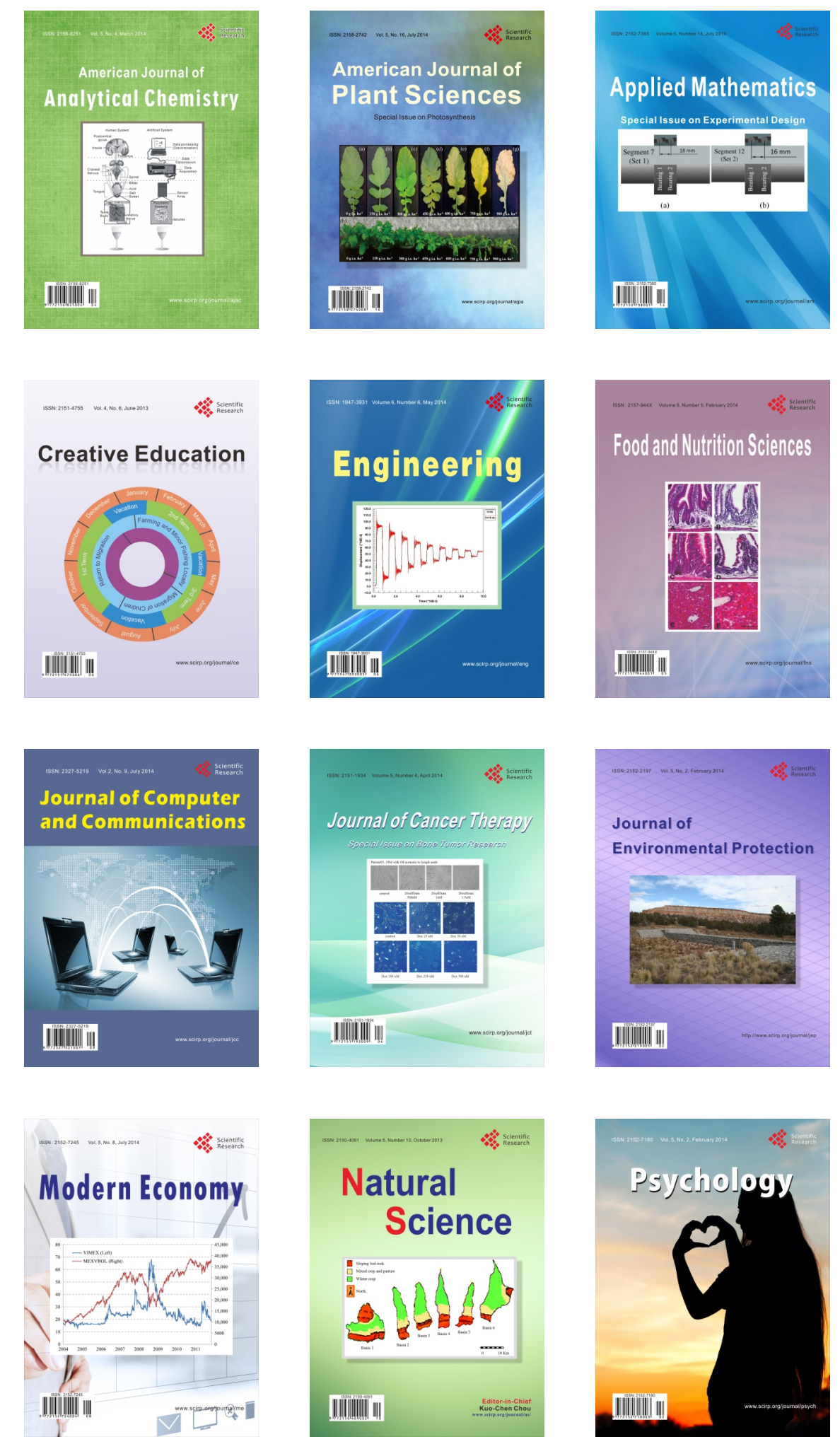